\title{
Outcomes of pregnancy in Egyptian women with multiple sclerosis in the new treatment era: a multi-center retrospective observational study
}

\author{
Ali Mahmoud Ahmed*i[, Mohamed Al-Bahay M. G. Reda and Ahmed Hassan Elsheshiny
}

\begin{abstract}
Background: Pregnancy is a recent growing issue in multiple sclerosis (MS) and the update in the diagnostic criteria of MS and introduction of many disease-modifying therapies (DMTs) may cause changes in the relationship between MS, pregnancy, and breastfeeding. This study aimed to investigate the effect of pregnancy and breastfeeding on MS and vice versa. A retrospective observational study was conducted to include MS women with a history of at least one pregnancy during the last 7 years. Data were collected from the archived files in addition to a self-administrating questionnaire. The annualized relapsing rate (ARR) was calculated before, during, and after pregnancy.

Results: We included 116 successful pregnancies from 93 MS women with mean age $32.74 \pm 5.12$ years. Interferonbeta was the commonly used DMT during and after pregnancy. Despite the ARR during the two years preceding the conception was 0.36 ( $95 \% \mathrm{Cl} 0.32-0.41)$, this rate was significantly decreased during first, second, and third trimester (0.07; 95\% Cl 0.04-0.15, 0.10; 95\% Cl 0.03-0.17, and 0.15; 95\% Cl 0.08-0.24, respectively; $P$-value < 0.001 in all). Furthermore, this ARR was significantly decreased during the first and last three months after delivery $(0.27 ; 95 \% \mathrm{Cl} 0.16-0.39$; $P$-value $=0.037$, and $0.24 ; 95 \% \mathrm{Cl} 0.17-0.38 ; P$-value $=0.023)$. Exclusive breastfeeding was associated with deceased risk of postpartum relapse, with HR 0.31 (95\% Cl0.12-0.67; $P=0.002$ ).

Conclusions: Pregnancy is protective from MS relapse, with a significant decrease of ARR from the pre-pregnancy period. Postpartum reactivation of the disease occurs from the third month after labor, rather than the early postpartum period. Exclusive breastfeeding for at least 2 months decreased the risk of postpartum relapse.
\end{abstract}

Keywords: Pregnancy, Multiple sclerosis, Disease modifying therapy, Breastfeeding

\section{Background}

Multiple sclerosis (MS) is an autoimmune disease affecting the central nervous system (CNS) of adults, especially women during the childbearing period [1]. Therefore, pregnancy-associated conditions like lactation are major concerns that should be discussed and studied in women with MS. There was a concept, that was retrieved from the previous literature, illustrating that women with relapsing remittent (RR) MS have a relatively lower risk of relapse during pregnancy than the pre-pregnancy

*Correspondence: ali.m.ahmed@azhar.edu.eg

Department of Neurology, Faculty of Medicine, Al-Azhar University,

ElMokhayam El Daem St., Cairo 11884, Egypt period. However, this risk would increase immediately postpartum to be higher in the pre-pregnancy period [2-5]. The mechanism of that assumption is not well known,however, it may be due to the decrease of cellular immunity and the increase of humoral immunity with shifting from Th1 to Th2 during pregnancy and the opposite occur after delivery, causing reactivation of the disease $[2,6]$. This concept was dependent on a previous work that was published more than a quarter of a century ago [2]. Therefore, this concept need revision as the MS diagnostic criteria was recently updated to include many women with mild symptoms at the early stages of the disease. 
This concept showed its direct effect on family planning, breastfeeding, and treatment choices due to the fear of postpartum relapse and the progression of disability. It is a hard choice for any MS woman to stop specific disease-modifying therapy (DMT), stop breastfeeding, or continue breastfeeding with the risk of affection by DMT. Resuming the DMT after pregnancy could decrease the risk of postpartum relapse but could affect the infant due to the discontinuation of breastfeeding, which has multiple benefits for the infant. There is no enough data regarding the effect of DMT on breastfeeding [7-9].

Many previous studies which tried to discuss this controversy showed many limitations included; small sample size, selection bias, and inefficient measure of study outcome (pregnancy and breastfeeding) [10-13]. A previous systematic review and meta-analysis studying the association between postpartum relapse and breastfeeding revealed that breastfeeding could protect from postpartum relapse [14]. This may be due to resuming DMT after labor, not due to the lactation. Other studies revealed that resuming DMT with the first two years, two months, or even the first year after delivery had no beneficial effect [7-9]. Therefore, this study aimed to investigate the correlation of pregnancy, labor, and lactation with relapse and disease progression in both RR and primary progressive MS. Furthermore, we aimed to investigate the effect of prior treatment with DMT on pregnancy and fatal outcomes and the relationship between DMTs and lactation.

\section{Methods}

This study was conducted as a retrospective observational study through which the data were obtained from the archived files of eligible participants. Furthermore, a study-specific questionnaire was introduced and filled by each participant. This study was conducted at MS units in three hospitals. This study was conducted in concordance with the declaration of Helsinki and each participant signed informed consent before being enrolled in the study. The institutional review board approval was obtained from our ethical committee.

Any known clinically definite MS (CDMS) female patient with childbearing potential (15-45 years old) with a history of at least one pregnancy during the last seven years was included in the study. The diagnosis of MS should be established at least one year before pregnancy.

Any female patient with an unconfirmed diagnosis or those who did not conceive during the last seven years was excluded from the study. Moreover, patients with other demyelinating diseases or any vasculitic or other autoimmune diseases were also excluded. Patients with EDSS score more than 6 at the enrolled time were also be omitted.
Demographic and clinical data including age, body mass index (BMI), time duration since MS diagnosis, comorbidities rather than MS, number of pregnancies, and abortions before and after MS diagnosis (in the last seven years) were considered. The Expanded Disability Status Scale (EDSS) was assessed at the time of presentation and compared with that has been measured during and before pregnancy. In addition to EDSS, disability was assessed at the time of enrollment and graded as; no disability, some disability but fully ambulatory (minimal disability), some ambulatory impairment, cane required, and wheelchair required [15]. Pre-conceptional data including the use of DMT, preparation for pregnancy, relapsing rate, and usage of fertility-associated medication, discontinuation of DMT before pregnancy, in the case of planned pregnancy, were also assessed. In addition, the pregnancy data including use of DMT during the initial period of unexpected pregnancy, relapsing rate during pregnancy, steroid therapy, abortion, preeclampsia, and other pregnancy-related outcomes were considered. Furthermore, the labor data including the type of delivery, the way of anesthesia, neonatal outcomes immediately after delivery, and delivery associated complications were considered. Furthermore, post-partum data including the $\mathrm{RR}$, using steroids as prophylaxis, breastfeeding outcome, and DMT used after delivery were considered.

The annualized relapsing rate (ARR) was calculated two years before conception, very trimester during pregnancy, and every three months after pregnancy. In the case of multiple pregnancies, the ARR was calculated by dividing all relapses that were happened in that period on the time per year $(0.33)$ and divide them by the total number of pregnancies. Breastfeeding was categorized into exclusive, mixed, and non, based on the data from the first two months postpartum. Survival analysis was used to assess the time to first relapse after delivery and hens the association between DMT resuming, and breastfeeding. Sensitivity analysis was used to assess the effect of disease severity on pregnancy outcomes, the used DMT and breastfeeding. Regression analysis was conducted to investigate the predictor factors of relapse either during pregnancy and postpartum with hazard ratio (HR) and $25 \%$ confidence interval $(\mathrm{CI})$.

Continuous variables will be represented as either means and standard deviation (SD) or median and interquartile range (IQR) according to their normality. Normal distribution was assessed using the Kolmogorov-Smirnov test. To compare the means between two groups, we used parametric ( $t$-test) and non-parametric tests (Mann-Whitney $U$ test), depending on the type of data distribution and the total number of patients in each group. Furthermore, the Wilcoxon test, the McNemar test, and the $t$-test were used for repeated measures 
to study the annualized relapsing rate over time (before, during, and after pregnancy). The association between qualitative variables was studied with the chi-square test or the Fisher exact test. Statistical analysis was conducted using SPSS version 24.0 and statistical significance was set at $P<0.05$.

\section{Results}

After fulfilling eligibility criteria, 116 successful pregnancies were included from $93 \mathrm{MS}$ women. The mean age of the included patients was $32.74 \pm 5.12$ years. Most of the included women were diagnosed with relapsing remittent MS (RRMS) with more than 55\% developed one or more relapses in the 2 years preceding the conception. The majority of the patients did not show disability or just showed minimal disability with DMT usage one year before the conception. Interferon beta was the most DMT used by the patients (Table 1).

Having the effect of MS on pregnancy and labor-related outcomes, the duration of pregnancy was lower after MS development $(P=0.041)$. Furthermore, the anesthesia was shifted from spinal to general anesthesia in most patients after MS development, and the mode of delivery was shifted from normal to cesarean in most patients after MS development. Moreover, the breastfeeding significantly decreased after MS development (Table 2).

Having the effect of pregnancy and its related issues on MS, the patients used DMTs intentionally in six pregnancies; however, DMTS were used accidentally, during the first trimester, in 38 pregnancies. Interferon-beta was the most commonly used DMT either intentionally or accidentally during pregnancy and postpartum. Having the postpartum relapse, about $20 \%$ of pregnancies reported one postpartum relapse, while $4.3 \%$ reported two postpartum relapses. The median time of postpartum relapses was 171 days (Table 3 ).

Having the relapsing rate, only 11 pregnancies reported one relapse during the period of pregnancy. Among them, eight patients accidentally exposed to fingolimod during the initial months of pregnancies then abruptly stopped. The remaining three patients included one who exposed accidentally to dimethyl fumarate, one exposed accidentally to rituximab, and one who was taking interferon beta but planned for pregnancy and did not expose accidentally to any DMT. On the other hands, 37 relapses had occurred during the first postpartum year of 36 pregnancies. Despite the ARR during the 2 years preceding the conception was 0.36 , this rate was significantly decreased during the first, second, and third trimesters $(P$-value $<0.001$ in all). Furthermore, this ARR was significantly decreased during the first and last three months after delivery $(P$-value $=0.023)$. However, this ARR did
Table 1 Demographic characteristics of the included 93MS women with 116 pregnancies

\begin{tabular}{|c|c|}
\hline Characteristic & Value \\
\hline Age (mean, SD), years & $32.74 \pm 5.12$ \\
\hline Disease duration, median (IQR), years & $4.5(1.93-8.92)$ \\
\hline \multicolumn{2}{|l|}{ MS subtype at onset of pregnancy, no. (\%) } \\
\hline RRMS & 109 (93.96\%) \\
\hline Progressive, relapsing MS & $7(6.03 \%)$ \\
\hline \multicolumn{2}{|c|}{ Relapses during 2 years before pregnancy ${ }^{a}$} \\
\hline 0 & $52(44.83 \%)$ \\
\hline 1 & $43(37.07 \%)$ \\
\hline$\geq 2$ & $21(18.10 \%)$ \\
\hline \multicolumn{2}{|l|}{ MS-related disability, no. (\%) } \\
\hline No disability & $70(60.34 \%)$ \\
\hline Some disability but fully ambulatory & $37(31.89 \%)$ \\
\hline Some ambulatory impairment & $7(6.03 \%)$ \\
\hline Cane required & $1(0.86 \%)$ \\
\hline Wheelchair required & $1(0.86 \%)$ \\
\hline \multicolumn{2}{|l|}{ EDSS score before pregnancy, no. (\%) } \\
\hline $0-0.5$ & $56(48.27 \%)$ \\
\hline $1-1.5$ & $39(33.63 \%)$ \\
\hline $2-2.5$ & $14(12.07 \%)$ \\
\hline $3-3.5$ & $5(4.31 \%)$ \\
\hline$\geq 4$ & $2(1.72 \%)$ \\
\hline \multicolumn{2}{|l|}{ DMT use before pregnancy, no. (\%) } \\
\hline Never & $18(15.52 \%)$ \\
\hline At the time of conception & $23(19.83 \%)$ \\
\hline Within 1 year prior & $75(64.65 \%)$ \\
\hline \multicolumn{2}{|l|}{ Type used within 1 year prior } \\
\hline Interferon-beta & $39(33.62 \%)$ \\
\hline Dimethyl fumarate & $7(6.03 \%)$ \\
\hline Natalizumab & $1(0.86 \%)$ \\
\hline Rituximab & $9(7.76 \%)$ \\
\hline Ocrelizumab & $4(3.45 \%)$ \\
\hline Fingolimod & $13(11.21 \%)$ \\
\hline Teriflunomide & $2(1.72 \%)$ \\
\hline \multicolumn{2}{|l|}{ Comorbidities other than MS } \\
\hline Hypertension & $8(6.89 \%)$ \\
\hline Diabetes mellitus & $1(0.86 \%)$ \\
\hline Others $^{\mathrm{a}}$ & $1(0.86 \%)$ \\
\hline
\end{tabular}

$D M T$ disease-modifying therapy; IQR interquartile range; $M S$ multiple sclerosis; RRMS relapsing-remitting MS; EDSS Expanded Disability Status Scale

${ }^{a}$ One case with deep venous thrombosis

not change during the middle 6 months of the year following the delivery (Table 4).

The pattern of ARR was shown to decrease during pregnancy and the three months following the delivery, then increase during the following six months and finally decrease again during the last three months of the first year following the delivery (Fig. 1). 
Table 2 Effect of MS on pregnancy and labor related outcomes

\begin{tabular}{|c|c|c|c|}
\hline & Before MS diagnosis & After MS diagnosis & $P$-value* \\
\hline No. of pregnancies & 39 & 116 & \\
\hline Planned & $27(69.2 \%)$ & $67(57.76 \%)$ & 0.204 \\
\hline Unplanned & $12(30.8 \%)$ & $49(42.24 \%)$ & \\
\hline Duration of pregnancy (months) & $9.4 \pm 0.27$ & $9.2 \pm 0.24$ & 0.041 \\
\hline No. of abortions & 13 & 19 & \\
\hline First trimester & $6(46.15 \%)$ & $11(57.89 \%)$ & 0.599 \\
\hline Second trimester & $3(23.08 \%)$ & $5(26.32 \%)$ & \\
\hline Third trimester & $4(30.77 \%)$ & $3(15.79 \%)$ & \\
\hline Pregnancy complications ${ }^{\mathrm{a}}$ & $7(17.95 \%)$ & $11(9.48 \%)$ & 0.153 \\
\hline Fetal complications & $1(14.29 \%)$ & $2(18.18 \%)$ & 0.829 \\
\hline Maternal complications & $6(85.71 \%)$ & $9(81.82 \%)$ & \\
\hline \multicolumn{4}{|l|}{ Anesthesia during labor } \\
\hline General & $2(5.13 \%)$ & $99(85.34 \%)$ & $<0.001$ \\
\hline Spinal & $37(94.87 \%)$ & $17(14.66 \%)$ & \\
\hline \multicolumn{4}{|l|}{ Type of delivery } \\
\hline Normal & $18(46.15 \%)$ & $7(6.03 \%)$ & $<0.001$ \\
\hline Cesarian & $21(53.85 \%)$ & $109(93.97 \%)$ & \\
\hline Complicated delivery & $3(7.79 \%)$ & $8(6.89 \%)$ & 0.867 \\
\hline \multicolumn{4}{|l|}{ Complications after delivery } \\
\hline Maternal ${ }^{b}$ & $0(0 \%)$ & $9(7.76 \%)$ & 0.247 \\
\hline Neonatal & $2(5.13 \%)$ & $4(3.45 \%)$ & \\
\hline \multicolumn{4}{|l|}{ Breast feeding after delivery } \\
\hline Non & $12(30.77 \%)$ & $48(41.68 \%)$ & 0.038 \\
\hline Exclusive for 2 months or more & $17(43.59 \%)$ & $26(22.41 \%)$ & \\
\hline Non-exclusive & $10(25.64 \%)$ & $42(36.21 \%)$ & \\
\hline \multicolumn{4}{|c|}{ Usage of contraception after delivery } \\
\hline Hormonal & $22(56.41 \%)$ & $72(62.07 \%)$ & 0.776 \\
\hline Physical & $15(38.46 \%)$ & $44(37.93 \%)$ & \\
\hline
\end{tabular}

MS multiple sclerosis

${ }^{\text {a }}$ Complications other than abortion

${ }^{\mathrm{b}}$ Other than relapses

*Level of significance is set when the $P$-value $<0.05$

The regression analysis revealed that exclusive breastfeeding is associated with decreased risk of postpartum relapse with HR $0.31(P=0.002)$, while nonexclusive breastfeeding did not show this association. Furthermore, the pre-pregnancy relapses were associated with an increased risk of relapse during pregnancy. Moreover, pregnancy relapses were associated with an increase in the risk of further relapses during the pregnancy and the following pregnancies $(P<0.001)$. Similar results were seen regarding the disability (Table 5).

\section{Discussion}

Pregnancy is a recent growing issue in MS since the past two centuries when pregnancy was hypothesized to protect from MS activities and relapse and the postpartum period was hypothesized to increase the risk of relapse and the disease activity especially during the initial months of this period. Till now, no standardized treatment to reduce the risk of this rebound, and there is no enough data as regards the usefulness of most DMTs in such period. Furthermore, the change in the diagnostic criteria of MS and the inclusion of milder cases may cause changes in that concept as regards the relationship between MS and pregnancy and breastfeeding. This observational study was conducted to investigate this relationship and the factors affecting it. We have found that the ARR decreased during pregnancy and returned to increase after labor to a level that exceeded the prepregnancy period. Furthermore, exclusive breastfeeding for at least two months decreased the risk of postpartum relapse; however, pre-pregnancy and pregnancy relapses in addition to the disability were shown to be predictive variables for increase the pregnancy and postpartum relapses. 
Table 3 The effect of pregnancy and labor on MS outcomes

\begin{tabular}{|c|c|}
\hline Characteristic & Total, $n=116$ \\
\hline \multicolumn{2}{|l|}{ Pregnancy } \\
\hline Relapse during pregnancy, no. (\%) & $13(11.21 \%)$ \\
\hline \multicolumn{2}{|l|}{ DMT use during pregnancy ${ }^{\mathrm{a}}$, no. (\%) } \\
\hline Intentionally & $6(5.17 \%)$ \\
\hline Accidentally (at first trimester) & $38(32.76 \%)$ \\
\hline \multicolumn{2}{|l|}{ DMT type used (Intentionally) } \\
\hline Interferon-beta & $5(83.33 \%)$ \\
\hline \multicolumn{2}{|l|}{ DMT type used (Accidentally) } \\
\hline Interferon-beta & $15(39.47 \%)$ \\
\hline Dimethyl fumarate & $7(18.42 \%)$ \\
\hline Fingolimod & $12(31.58 \%)$ \\
\hline Rituximab & $3(7.89 \%)$ \\
\hline ocrelizumab & $1(2.63 \%)$ \\
\hline \multicolumn{2}{|l|}{ Postpartum period } \\
\hline \multicolumn{2}{|l|}{ No. of pregnancies with postpartum relapses, no. (\%) } \\
\hline 0 & $85(73.28 \%)$ \\
\hline 1 & $24(20.69 \%)$ \\
\hline 2 & $5(4.31 \%)$ \\
\hline$\geq 3$ & $2(1.72 \%)$ \\
\hline Time to first postpartum relapse ${ }^{b}$, median (IQR), days & $171(78-232)$ \\
\hline \multicolumn{2}{|l|}{ DMT use during postpartum year, no. (\%) } \\
\hline None & $69(59.48 \%)$ \\
\hline Interferon-beta & $22(18.97 \%)$ \\
\hline Dimethyl fumarate & $7(6.03 \%)$ \\
\hline Natalizumab & $3(2.57 \%)$ \\
\hline Rituximab & $4(3.45)$ \\
\hline Fingolimod & $8(6.90 \%)$ \\
\hline Ocrelizumab & $3(2.57 \%)$ \\
\hline Time to restart DMT after delivery ${ }^{c}$ (median, IQR), $d$ & $86(29-201)$ \\
\hline
\end{tabular}

The reduced risk of postpartum relapse was obvious in the first 6 months postpartum and was independent of the pre-pregnancy disease activity, as it was shown in women with suboptimal disease control pre-pregnancy active disease. Interestingly, the use of DMTs either pre-pregnancy or immediately after pregnancy did not show to affect the ARR during pregnancy or after labor. These results were concomitant with a recently published cohort [16]. However, most women forego breastfeeding, either exclusive or non-exclusive, after MS development. This could be due to the fear of the risk of MS relapse or they to start DMT. These results were against the results that were revealed by Langer-Gould and colleagues who revealed that MS wanted to continue breastfeeding after MS development [16].

About two-thirds of the included pregnancies were associated with at least one MS relapse during the prepregnancy 2 years. Despite the control of MS was suboptimal in these women, they conceived without fear of disease activity. However, this could be problematic as the pre-pregnancy MS relapse was a predictive factor of MS relapse during pregnancy and postpartum. These results were shown in previously published studies $[2,7,16-18]$. This courage to conceive could be due to the absence of disability, as about $70 \%$ of our patients were free of disability, the presence of a large fraction of unplanned pregnancies, and lack of periconceptional consultation. Langer-Gould and colleagues revealed that the presence of disability or residuals from the attacks were predictors of long-term poor outcome [19].

The use of DMT is a considerable challenge during pregnancy and postpartum. Interferon beta was proven to be safe DMTs during and after pregnancy [20]. Similarly, natalizumab showed encouraging results without any risk of abortion or fetal complications [21, 22]. There is no enough data as regards the effect of

Table 4 Relapse rates before, during, and after pregnancy

\begin{tabular}{|c|c|c|c|c|}
\hline & No. pregnancies & No. relapses & $\begin{array}{l}\text { Rate of relapse/pregnancies/ } \\
y^{a}\end{array}$ & $P$ value* \\
\hline 2 years before pregnancy & 63 & 84 & $0.36(0.32-0.41)$ & - \\
\hline \multicolumn{5}{|l|}{ Pregnancy } \\
\hline First trimester & 2 & 2 & $0.07(0.04-0.15)$ & $<0.001$ \\
\hline Second trimester & 3 & 3 & $0.10(0.03-0.17)$ & $<0.001$ \\
\hline Third trimester & 6 & 6 & $0.15(0.08-0.24)$ & $<0.001$ \\
\hline \multicolumn{5}{|l|}{ Year after pregnancy } \\
\hline Months 1-3 & 8 & 8 & $0.27(0.16-0.39)$ & 0.037 \\
\hline Months 4-6 & 11 & 11 & $0.38(0.26-0.52)$ & 0.990 \\
\hline Months 7-9 & 10 & 11 & $0.38(0.26-0.52)$ & 0.751 \\
\hline Months 10-12 & 7 & 7 & $0.24(0.17-0.38)$ & 0.023 \\
\hline
\end{tabular}

${ }^{\mathrm{a}}$ Mean and $95 \%$ confidence intervals

* Compared with 2 years before pregnancy, generalized estimation equations were used to account for women with multiple pregnancies. Level of significance is set when the $P$-value $<0.05$ 


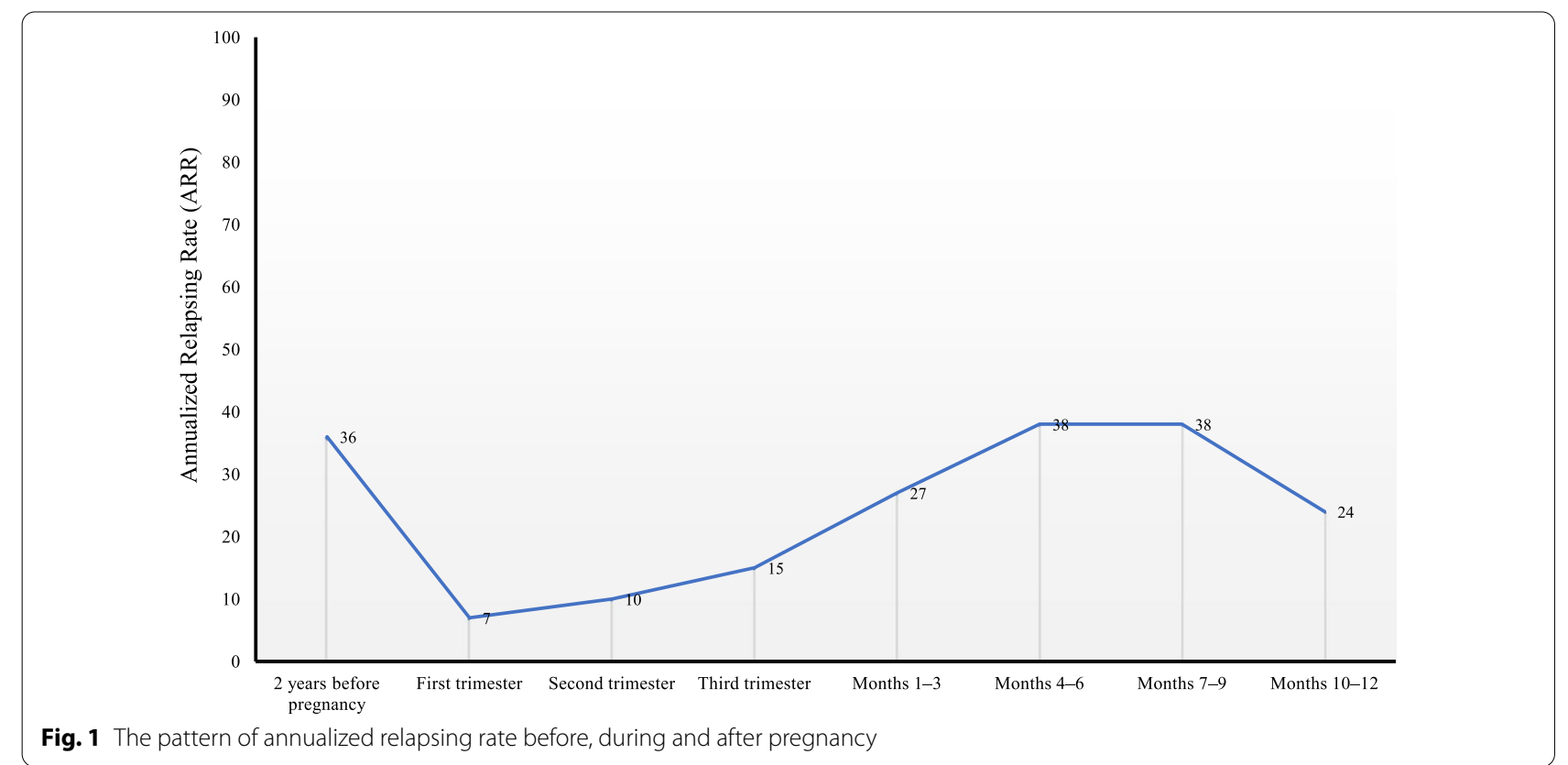

Table 5 Regression analysis of factors associated with increase the risk of MS relapse

\begin{tabular}{|c|c|c|}
\hline & Hazard ratio $(95 \% \mathrm{Cl})^{\mathrm{a}}$ & $\begin{array}{l}p \\
\text { Value* }\end{array}$ \\
\hline No breastfeeding & 1.0 (ref) & \\
\hline Exclusive breastfeeding ${ }^{b}$ & $0.31(0.12-0.67)$ & 0.002 \\
\hline Nonexclusive breastfeeding ${ }^{b}$ & $0.59(0.31-1.16)$ & 0.126 \\
\hline Pre-pregnancy relapses ${ }^{c}$ & $2.21(1.23-3.69)$ & 0.005 \\
\hline $\begin{array}{l}\text { Use of DMT before pregnancy by } \\
1 \text { year }\end{array}$ & $1.46(0.90-2.38)$ & 0.130 \\
\hline Pregnancy relapse & $3.09(1.68-5.67)$ & $<0.001$ \\
\hline Use of postpartum DMT ${ }^{d}$ & $1.41(0.71-2.58)$ & 0.340 \\
\hline Age, (years) & $0.92(0.89-0.99)$ & 0.016 \\
\hline Disease duration, (years) & $1.12(0.96-1.23)$ & 0.437 \\
\hline Disability ${ }^{e}$ & $2.08(1.72-3.41)$ & 0.002 \\
\hline
\end{tabular}

Clconfidence interval; DMT disease-modifying therapy; MS multiple sclerosis

${ }^{a}$ Cox proportional hazards model $/{ }^{*}$ Level of significance is set when the P-value $<0.05$

${ }^{\mathrm{b}}$ Reference group no breastfeeding

' Reference group 0-1 relapse in 2 years before pregnancy

${ }^{\mathrm{d}}$ Time-dependent covariate

e Reference group no MS-related disability at pregnancy onset

remaining DMT on pregnancy and breastfeeding [23]. Rituximab was shown to be helpful during breastfeeding, but not pregnancy, in women with highly active disease $[24,25]$. Therefore, it is recommended to start in such patients 6-12 months after labor [24]. Our results regarding the absence of DMT usage and postpartum disease activity were concomitant with previous studies that included women who resumed DMT as early as the first two weeks of the first postpartum year $[7-9,16]$. These studies included more advanced cases than our study.

Among the 12 women who were exposed accidentally to fingolimod, eight patients developed MS relapses during pregnancy, and all of them developed postpartum relapses even after retained the DMT. This may be due to the rebound increase in the disease activity after sudden cessation of fingolimod [26]. Despite the fingolimod is known to be teratogenic, our study showed that only one case was associated with a mild fetal abnormality. These results were concomitant with a recent study which demonstrated that there was no difference between fingolimod and interferon-beta as regards the major fetal complications [27].

The reported ARR during pregnancy and postpartum in our study was lower than that was reported in the previous studies $[7,9,12,13]$. This may be due to the recent update in the MS diagnostic criteria and the inclusion of many milder cases. In previous studies, the inclusion of patients was dependent on the presence of two or more attacks, but after the 2017 updates of the MS diagnostic criteria, many cases with CIS were considered as MS. This inclusion of many milder cases resulted in a considerable decrease in the ARR in many previous studies, from 0.84 to $0.36[28,29]$. Our results were comparable with the previous Turkish study which revealed the rate of relapse decreased during pregnancy,however, it was higher in the first trimester than the subsequent two trimesters [30]. On the other hand, our study showed that the third trimester was associated with the highest ARR. 
Furthermore, this study revealed that the multiple pregnancies were associated with higher EDSS score, though, none of the patients did not reach score 6 . On the other hands, the patients with multiple pregnancies in our sample were associated with relatively milder form of the disease than other patients. This can be logic as younger patients develop milder forms of the disease and tend to be pregnant more than one time.

The postpartum ARR was lower than what is expected in the first three months after delivery. These results were concomitant with the previous cohort [16]. This may be due to the increased rate of exclusive breastfeeding in that study. However, the rate of breastfeeding in our study was lower than that study. The inclusion of milder cases without any disability may also play a role in the decreased early postpartum ARR. This indicating that breastfeeding is highly recommended in women with active disease, while in women with a relatively milder disease the postpartum ARR is decreased regardless the breastfeeding.

Having the effect of MS on pregnancy, the decrease in the pregnancy duration after MS development was not concomitant with the previous studies [31]. This may be due to the fear of obstetric complications which is a national problem and wrong conception to the obstetricians due to the lack of health education. This concept resulted in the increase of cesarean section rates after MS development, even if not indicated. Furthermore, the decrease in the rate of breastfeeding after MS development may be due to the fear of postpartum rebound or the intuition to resume the DMT.

\section{Conclusions}

This study highlighted that pregnancy is protective from MS relapse, with a significant decrease of ARR from the pre-pregnancy period. Postpartum reactivation of the disease occurs from the third month after labor rather than the early postpartum period. Exclusive breastfeeding for at least two months decreased the risk of postpartum relapse; however, pre-pregnancy and pregnancy relapses in addition to the disability were shown to be predictive variables for increase the pregnancy and postpartum relapses. DMT has no role in decreasing postpartum relapse. Health education and consultation should be performed to promote pregnancy and exclusive breastfeeding in women with MS even if they have advanced disease.

\section{Abbreviations}

MS: Multiple sclerosis; DMTs: Disease modifying therapies; ARR: Annualized relapsing rate; CNS: Central nervous system; RRMS: Relapsing remittent MS;
CDMS: Clinically definite MS; EDSS: Expanded Disability Status Scale; HR: Hazard ratio; Cl: Confidence interval; IQR: Interquartile range.

\section{Acknowledgements}

Not applicable.

\section{Authors' contributions}

AMA participated in hypothesis generating, data collection, data analysis, and manuscript writing. MAMGR proposed the idea, tested the hypothesis, and revised the extracted data, data analysis and manuscript. AHE participated in hypothesis generating, data collection, data analysis, and manuscript writing. 'All authors have read and approved the manuscript.

Funding

This study was self-funded by the authors.

\section{Availability of data and materials}

The datasets analysed during the current study are not publicly available as the participants requested that, but are available from the corresponding author on reasonable request.

\section{Declarations}

\section{Ethics approval and consent to participate}

This study was conducted in concordance with declaration of Helsinki and each participant signed a written informed consent before being enrolled in the study. The institutional review board (IRB) approval was obtained from the ethical committee of Faculty of Medicine for boys, Al-Azhar University, Cairo on 14th April, 2020. There was no reference number provided by our IRB.

\section{Consent for publication \\ Not applicable.}

\section{Competing interests}

The authors declare that they have no competing interests.

Received: 21 July 2021 Accepted: 9 September 2021

Published online: 23 September 2021

References

1. Vukusic S, Hutchinson M, Hours M, Moreau T, Cortinovis-Tourniaire P, Adeleine $\mathrm{P}$, et al. Pregnancy and multiple sclerosis (the PRIMS study): clinical predictors of post-partum relapse. Brain J Neurol. 2004;127:1353-60.

2. Confavreux C, Hutchinson M, Hours MM, Cortinovis-Tourniaire P, Moreau T. Rate of pregnancy-related relapse in multiple sclerosis. Pregnancy in Multiple Sclerosis Group. N Engl J Med. 1998;339:285-91.

3. Finkelsztejn A, Brooks JB, Paschoal FM Jr, Fragoso YD. What can we really tell women with multiple sclerosis regarding pregnancy? A systematic review and meta-analysis of the literature. BJOG Int J Obstetr Gynaecol. 2011;118:790-7. https://doi.org/10.1111/j.1471-0528.2011.02931.x.

4. Berenguer-Ruiz L, Gimenez-Martinez J, Palazón-Bru A, Sempere AP. Relapses and obstetric outcomes in women with multiple sclerosis planning pregnancy. J Neurol. 2019;266:2512-7. https://doi.org/10.1007/ s00415-019-09450-6.

5. Bsteh G, Algrang L, Hegen H, Auer M, Wurth S, Di Pauli F, et al. Pregnancy and multiple sclerosis in the DMT era: a cohort study in Western Austria. Multiple Scler. 2020;26:69-78. https://doi.org/10.1177/1352458518 816614.

6. Confavreux C. Intravenous immunoglobulins, pregnancy and multiple sclerosis. J Neurol. 2004:251(9):1138-9.

7. Portaccio E, Ghezzi A, Hakiki B, Sturchio A, Martinelli V, Moiola L, et al. Postpartum relapses increase the risk of disability progression in multiple sclerosis: the role of disease modifying drugs. J Neurol Neurosurg Psychiatry. 2014;85:845-50.

8. Beaber BE, Chi MD, Brara SM, Zhang JL, Langer-Gould AM. Immunomodulatory agents and risk of postpartum multiple sclerosis relapses. Perm J. 2014;18:9-13. 
9. Hellwig K, Rockhoff M, Herbstritt S, Borisow N, Haghikia A, Elias-Hamp $B$, et al. Exclusive breastfeeding and the effect on postpartum multiple sclerosis relapses. JAMA Neurol. 2015;72:1132-8.

10. Portaccio E, Ghezzi A, Hakiki B, Martinelli V, Moiola L, Patti F, et al. Breastfeeding is not related to postpartum relapses in multiple sclerosis. Neurology. 2011;77:145-50.

11. Langer-Gould A, Huang SM, Gupta R, Leimpeter AD, Greenwood E, Albers $K B$, et al. Exclusive breastfeeding and the risk of postpartum relapses in women with multiple sclerosis. Arch Neurol. 2009;66:958-63.

12. Airas L, Jalkanen A, Alanen A, Pirttila T, Marttila RJ. Breast-feeding, postpartum and prepregnancy disease activity in multiple sclerosis. Neurology. 2010;75:474-6.

13. Jesus-Ribeiro J, Correia I, Martins Al, Fonseca M, Marques I, Batista S, et al. Pregnancy in multiple sclerosis: a Portuguese cohort study. Mult Scler Relat Disord. 2017;17:63-8.

14. Pakpoor J, Disanto G, Lacey MV, Hellwig K, Giovannoni G, Ramagopalan SV. Breastfeeding and multiple sclerosis relapses: a meta-analysis. J Neurol. 2012;259:2246-8.

15. Kister I, Chamot E, Salter AR, Cutter GR, Bacon TE, Herbert J. Disability in multiple sclerosis: a reference for patients and clinicians. Neurology. 2013;80(11):1018-24.

16. Langer-Gould A, Smith JB, Albers KB, Xiang AH, Wu J, Kerezsi EH, et al. Pregnancy-related relapses and breastfeeding in a contemporary multiple sclerosis cohort. Neurology. 2020;94:e1939-49.

17. Vukusic S, Hutchinson M, Hours M, Moreau T, Cortinovis-Tourniaire P, Adeleine $P$, et al. Pregnancy and multiple sclerosis (the PRIMS study): clinical predictors of post-partum relapse. Brain. 2004;127(1353-1360):16.

18. Hughes SE, Spelman T, Gray OM, Boz C, Trojano M, Lugaresi A, et al. Predictors and dynamics of postpartum relapses in women with multiple sclerosis. Mult Scler. 2014;20:739-46.

19. Langer-Gould A, Popat RA, Huang SM, Cobb K, Fontoura P, Gould MK, et al. Clinical and demographic predictors of long-term disability in patients with relapsing-remitting multiple sclerosis: a systematic review. Arch Neurol. 2006;63:1686-91.

20. Hellwig K, Geissbuehler Y, Sabidó M, Popescu C, Adamo A, Klinger J, et al. Pregnancy outcomes in interferon-beta-exposed patients with multiple sclerosis: results from the European Interferon-beta Pregnancy Registry. J Neurol. 2020;267(6):1715-23.
21. Friend S, Richman S, Bloomgren G, Cristiano LM, Wenten M. Evaluation of pregnancy outcomes from the Tysabri ${ }^{\circledR}$ (natalizumab) pregnancy exposure registry: a global, observational, follow-up study. BMC Neurol. 2016;16(1):1-9.

22. Portaccio E, Annovazzi P, Ghezzi A, Zaffaroni M, Moiola L, Martinelli V, et al. Pregnancy decision-making in women with multiple sclerosis treated with natalizumab: I: Fetal risks. Neurology. 2018;90(10):e823-31.

23. Bsteh G, Algrang L, Hegen H, Auer M, Wurth S, Di Pauli F, et al. Pregnancy and multiple sclerosis in the DMT era: a cohort study in Western Austria. Mult Scler J. 2020;26(1):69-78.

24. Langer-Gould AM. Pregnancy and family planning in multiple sclerosis. Continuum (Minneap Minn). 2019;25:773-92.

25. Smith JB, Hellwig K, Fink K, Lyell DJ, Piehl F, Langer-Gould A. Rituximab, MS, and pregnancy. Neurology. 2020;7(4):1.

26. Hatcher SE, Waubant E, Nourbakhsh B, Crabtree-Hartman E, Graves JS. Rebound syndrome in patients with multiple sclerosis after cessation of fingolimod treatment. JAMA Neurol. 2016;73(7):790-4.

27. Pauliat E, Onken M, Weber-Schoendorfer C, Rousson V, Addor MC, Baud $D$, et al. Pregnancy outcome following first-trimester exposure to fingolimod: a collaborative ENTIS study. Mult Scler. 2021:27(3):475-8.

28. Johnson KP, Brooks BR, Cohen JA, Ford CC, Goldstein J, Lisak RP, et al. Copolymer 1 reduces relapse rate and improves disability in relapsingremitting multiple sclerosis: results of a phase III multicenter, doubleblind placebo-controlled trial. The Copolymer 1 Multiple Sclerosis Study Group. Neurology. 1995;45:1268-76.

29. Gold R, Kappos L, Arnold DL, Bar-Or A, Giovannoni G, Selmaj K, et al. Placebo-controlled phase 3 study of oral BG-12 for relapsing multiple sclerosis. N Engl J Med. 2012;367:1098-107.

30. Altintas A, Najar B, Gozubatik-Celik G, Menku SF. Pregnancy data in a Turkish multiple sclerosis population. Eur Neurol. 2015;74(5-6):296-302.

31. Novo A, Castelo J, de Sousa A, Amorim I, Alves JN, Calejo M, et al. Pregnancy outcomes in Portuguese women with multiple sclerosis: The PREGNIMS study. Mult Scler Relat Disord. 2019;28:172-6.

\section{Publisher's Note}

Springer Nature remains neutral with regard to jurisdictional claims in published maps and institutional affiliations.

\section{Submit your manuscript to a SpringerOpen ${ }^{\circ}$ journal and benefit from:}

- Convenient online submission

- Rigorous peer review

- Open access: articles freely available online

- High visibility within the field

- Retaining the copyright to your article

Submit your next manuscript at springeropen.com 